Boletín de la Sociedad Geológica Mexicana

VOLUMEN 66, NÚM. 2, 2014, P. 291-304

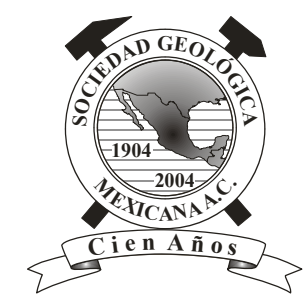

\title{
Neotectónica de la provincia de San Juan, centro-oeste de Argentina
}

\author{
Laura P. Perucca ${ }^{1, *}$, Nicolás Vargas ${ }^{2}$ \\ ${ }^{1}$ CONICET. Gabinete de Neotectónica y Geomorfología. Instituto de Geología. Facultad de Ciencias Exactas, Físicas y Naturales \\ Universidad Nacional de San Juan. \\ ${ }^{2}$ Departamento de Geología, Instituto de Geología. Facultad de Ciencias Exactas, Físicas y Naturales Universidad Nacional de San \\ Juan. CHISÑANCO SRL. San Juan. \\ *1perucca@unsj-cuim.edu.ar
}

\begin{abstract}
Resumen
La provincia de San Juan, en el centro-oeste de Argentina, posee numerosas evidencias de fallas con actividad tectónica cuaternaria. Las discontinuidades estructurales a lo largo de Cordillera Frontal, Precordillera y Sierras Pampeanas, determinan las diferentes características superficiales de las deformaciones cuaternarias, que a la vez producen distintos escenarios paleosísmicos. La mayor parte de estas deformaciones y estructuras sismogénicas, actualmente conocidas en el territorio argentino, se ubican dentro de un cinturón sísmico definido entre Cordillera Frontal y Sierras Pampeanas Occidentales $\left(27^{\circ}-33^{\circ}\right.$ de latitud sur). Esta región también constituye un área con interacciones complejas entre estilos estructurales de piel fina y gruesa. Los sismos más destructivos en los últimos 120 años (M 7.5, en octubre de 1894; M 7.0, en enero de 1944; 6.8, en junio de 1952; y M 7.4 en noviembre de 1977) se han ubicado en esta zona.

En este trabajo se presenta una síntesis del estado del conocimiento neotectónico de la provincia de San Juan, con los resultados de los últimos estudios sobre fallas con actividad tectónica cuaternaria en la región.
\end{abstract}

Palabras clave: neotectónica, terremoto, falla, magnitud, intensidad.

\begin{abstract}
San Juan province in central-western Argentina shows evidence of active faulting affecting Quaternary sediments. The structural discontinuities along the Frontal Cordillera, Precordillera and Sierras Pampeanas foothills determine the different superficial characteristics of the Quaternary deformations, which in turn produce different paleoseismic scenarios. Most the Quaternary deformations and seismogenic structures currently known in Argentina are located within a seismic belt including the Precordillera and the Western Pampean Ranges $\left(27^{\circ}-33^{\circ}\right.$ south latitude). This area also constitutes a setting with complex interactions between thin-skinned and thick-skinned structural styles. The most destructive earthquakes of the last 120 years (M 7.5, October 1894; M 7.0, January 1944; 6.8, June 1952; and M 7.4, November 1977) were located in this region.

This paper presents an overview of the state of knowledge on the neotectonics of the San Juan province, with the results from recent studies on faults with Quaternary tectonic activity in the region.
\end{abstract}

Keywords: neotectonics, earthquake, fault, magnitude, intensity. 


\section{Introducción}

La evolución estructural, en la región ubicada entre los $28^{\circ}$ y $33^{\circ} \mathrm{S}$ de los Andes, es el resultado de la convergencia entre las placas de Nazca y América del Sur. Esta convergencia dio origen a un estilo de deformación de piel gruesa (thick skinned belt) en la Cordillera Frontal, una faja plegada y corrida con deformación de piel delgada (thin skinned fold and thrust belt) en la Precordillera, y nuevamente un estilo tectónico de piel gruesa (thick-skinned) en las Sierras Pampeanas. En esta zona, la geometría sub-horizontal de la placa de Nazca es atribuida a la subducción de la dorsal Juan Fernández por debajo de la placa de América del Sur (Pilger, 1981; Anderson et al., 2007; Figura 1a).

La provincia de San Juan, ubicada en el centro-oeste de Argentina, posee la mayor evidencia de deformación cuaternaria de Argentina. Bastías (1986), agrupó estas estructuras cuaternarias en Sistemas de Falla, relacionados con los límites de las principales unidades geológicas. Costa et al. (2000) y Casa et al. (2011) efectuaron la recopilación de las principales trazas con actividad cuaternaria en el territorio argentino, y Perucca y Paredes (2004), efectuaron una descripción de las fallas activas ubicadas en la provincia de San Juan.

Las estructuras cuaternarias y sismogénicas actualmente conocidas entre $\operatorname{los} 28^{\circ}$ y $33^{\circ} \mathrm{S}$ se ubican dentro de un cinturón definido entre la Cordillera Frontal y las Sierras Pampeanas Occidentales, principalmente en la región de Precordillera (Figura 1b). Teniendo en cuenta la profundidad a la que se generan los eventos sísmicos, se reconocen sismos corticales $(5-35 \mathrm{~km})$, intermedios $(>35-120$ $\mathrm{km})$ y profundos $(>120 \mathrm{~km})$, siendo los dos primeros los que sobresalen por la cantidad de registros (Perucca et al., 2006) (Figura 1b). Los sismos de profundidad intermedia tienen una amplia concentración dentro de la Precordillera sanjuanina, principalmente en su porción central, hasta el borde occidental de la sierra de Pie de Palo.

Los terremotos más destructivos ocurridos en el país (M 7.5 en 1894; M 7.0 en 1944, 6.8 en 1952 y M 7.5 en 1977) se han ubicado en esta región (Figura 1c).

El 27 de octubre 1894, ocurrió un sismo de magnitud 7.5 (Bastías, 1986) y profundidad $30 \mathrm{~km}$ (INPRES, 2009), de carácter ondulatorio y larga duración. Su intensidad máxima fue IX (EMM) y causó alarma en gran parte de la Argentina, percibiéndose con distinta intensidad en Chile, sur de Brasil y Perú (INPRES 1993, 2009; Perucca et al., 2006) (Figura 2a). Algunas particularidades de este sismo fueron las grandes manifestaciones superficiales aún en áreas muy alejadas del epicentro, como licuefacción y agrietamiento del terreno (Bodenbender, 1895) (Figura 2b). El epicentro de este terremoto fue localizado en el área norte de la provincia, posiblemente asociado a la falla La Bolsa, aunque no se han podido reconocer rupturas superficiales (Perucca et al., 1999).

El 15 de enero de 1944 se produjo un sismo que duró 15 o 20 segundos y destruyó la ciudad de San Juan casi completamente. Alcanzó una magnitud Ms 7.0, una intensidad IX (EMM) y profundidad de $30 \mathrm{~km}$ (INPRES, 1993, 2009; Alvarado y Beck, 2006) (Figura 2c). La zona de máxima intensidad fue comparativamente reducida y abarcó aproximadamente $200 \mathrm{~km}^{2}$. El epicentro fue ubicado a $20 \mathrm{~km}$ al norte de la ciudad y el sismo fue percibido en otras ciudades de Argentina. Aproximadamente el $80 \%$ de los edificios fueron destruidos y murieron unas 10000 personas (INPRES, 1993; Perucca et al., 2006). En la falla La Laja, Harrington (1944) midió, luego del sismo, un desplazamiento vertical máximo de $22 \mathrm{~cm}$ y uno horizontal de $25 \mathrm{~cm}$. Castellanos (1945) observó una escarpa de 0.30 m luego del sismo, que "creció" a 0.60 m en los meses subsiguientes. Durante el terremoto de 1944 también se registraron numerosos fenómenos de licuefacción en los alrededores de la ciudad de San Juan (Perucca y Moreiras, 2006).

El 10 de junio de 1952 se produjo un terremoto de magnitud Ms 6.8 (Alvarado y Beck, 2006) e intensidad VIII, a una profundidad de $30 \mathrm{~km}$ (INPRES, 2009) (Figura 2d). Si bien fue un evento de moderada a elevada magnitud, hubo escasas víctimas fatales (Perucca et al., 2006). El sismo fue percibido en una extensa región que abarcó parte de Chile y este de Argentina, y fue asociado a la falla Rinconada, aunque no se encontraron evidencias de ruptura superficial durante este evento (Tello y Perucca, 1993).

El 23 de noviembre de 1977, se produjo un terremoto de larga duración que afectó la región centro-oeste de la Argentina y se percibió en gran parte del territorio, en el centro de Chile y hasta en el sur de Brasil (Figura 2e). Este terremoto se generó por un mecanismo denominado de evento múltiple, ya que ocurrieron dos terremotos, el primero disparador del segundo. El primer evento fue de magnitud Ms 6.6 y su epicentro se ubicó al noreste de la sierra de Pie de Palo, a una profundidad de $17 \mathrm{~km}$. Segundos más tarde, se produjo el terremoto principal de magnitud Ms 7.4 intensidad IX (MM) y epicentro en el extremo sudeste de la sierra de Pie de Palo, a una profundidad de $25 \mathrm{~km}$ (INPRES, 1993, 1977). Produjo 65 víctimas fatales y al igual que en los sismos anteriores, ocurrieron fenómenos de licuefacción y agrietamiento del terreno (Figura 2f) (Perucca y Moreiras, 2006; Perucca et al., 2006). Este evento se asocia al sistema de fallamiento AmpacamaNiquizanga, durante el cual se produjo ruptura superficial y un desplazamiento vertical promedio de $30 \mathrm{~cm}$, según un relevamiento geodésico efectuado en 1982 (Bastías, 1986).

En este trabajo se presenta una síntesis del estado actual del conocimiento de las fallas con actividad cuaternaria en provincia de San Juan. Se han recopilado estudios realizados por diversos autores relativos a las fallas activas $\mathrm{y}$ deformaciones verticales y horizontales actuales.

\section{Marco geológico y sismotectónico}

La Cordillera Frontal, cordón montañoso ubicado en la 
porción occidental de la provincia de San Juan (Groeber, 1951), comprende principalmente depósitos neopaleozoicos de ambiente marino (Amos y Rolleri, 1965), con intrusivos y volcánicos interdigitados, en sectores parcialmente cubiertos por sedimentos y rocas efusivas del PaleógenoNeógeno. El estilo tectónico es complejo, representado
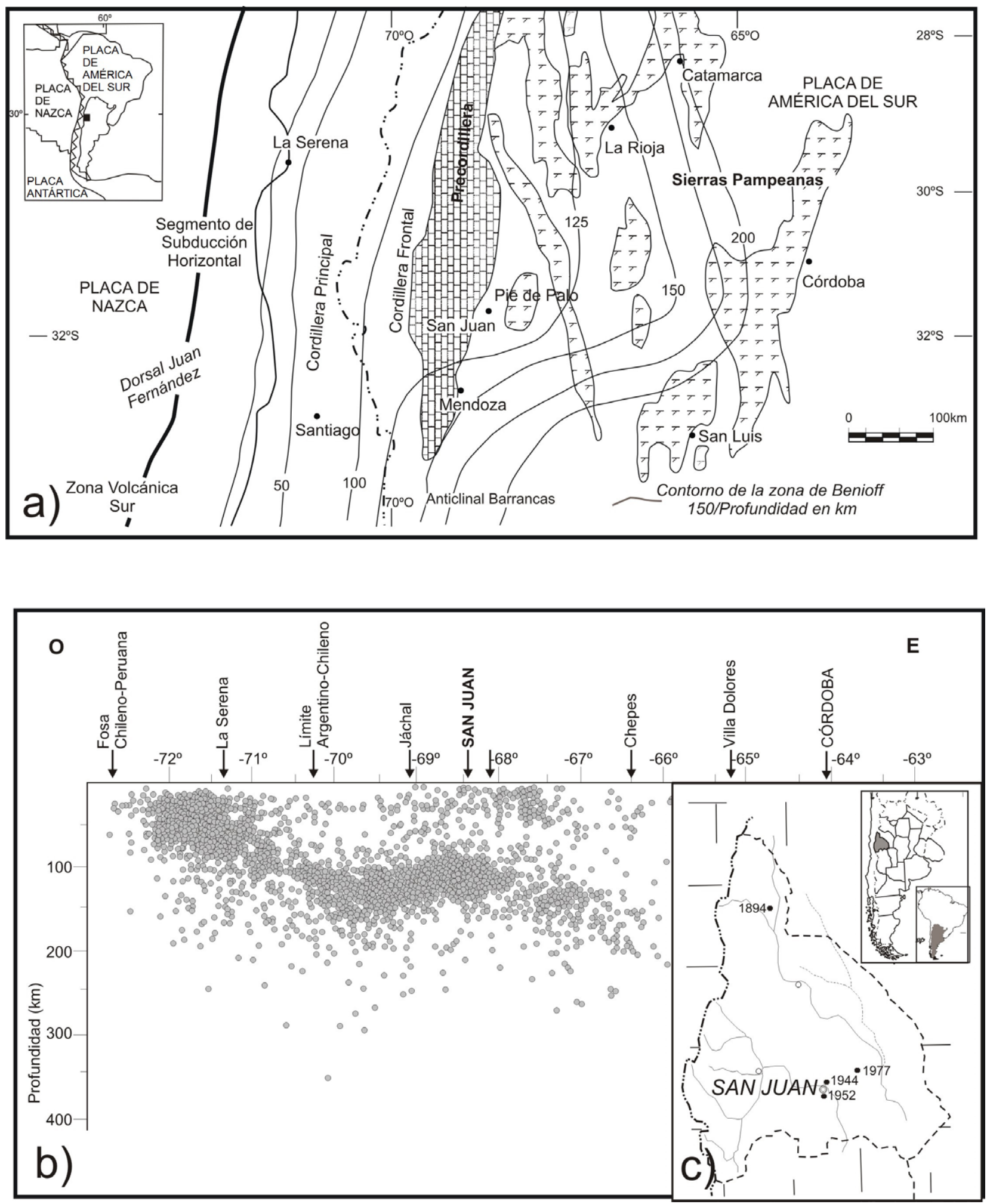

Figura 1. a) Ubicación del segmento de subducción plana entre los $28^{\circ}$ y $32^{\circ} \mathrm{S}$ con los contornos de la profundidad de subducción (Modificado de Ramos et al., 2000), b) Perfiles oeste-este con la actividad símica entre $28^{\circ}$ y $33^{\circ} 30^{\prime}$ LS (Modificado de INPRES, 1993), c) Localización de los principales terremotos destructivos en la provincia de San Juan. 

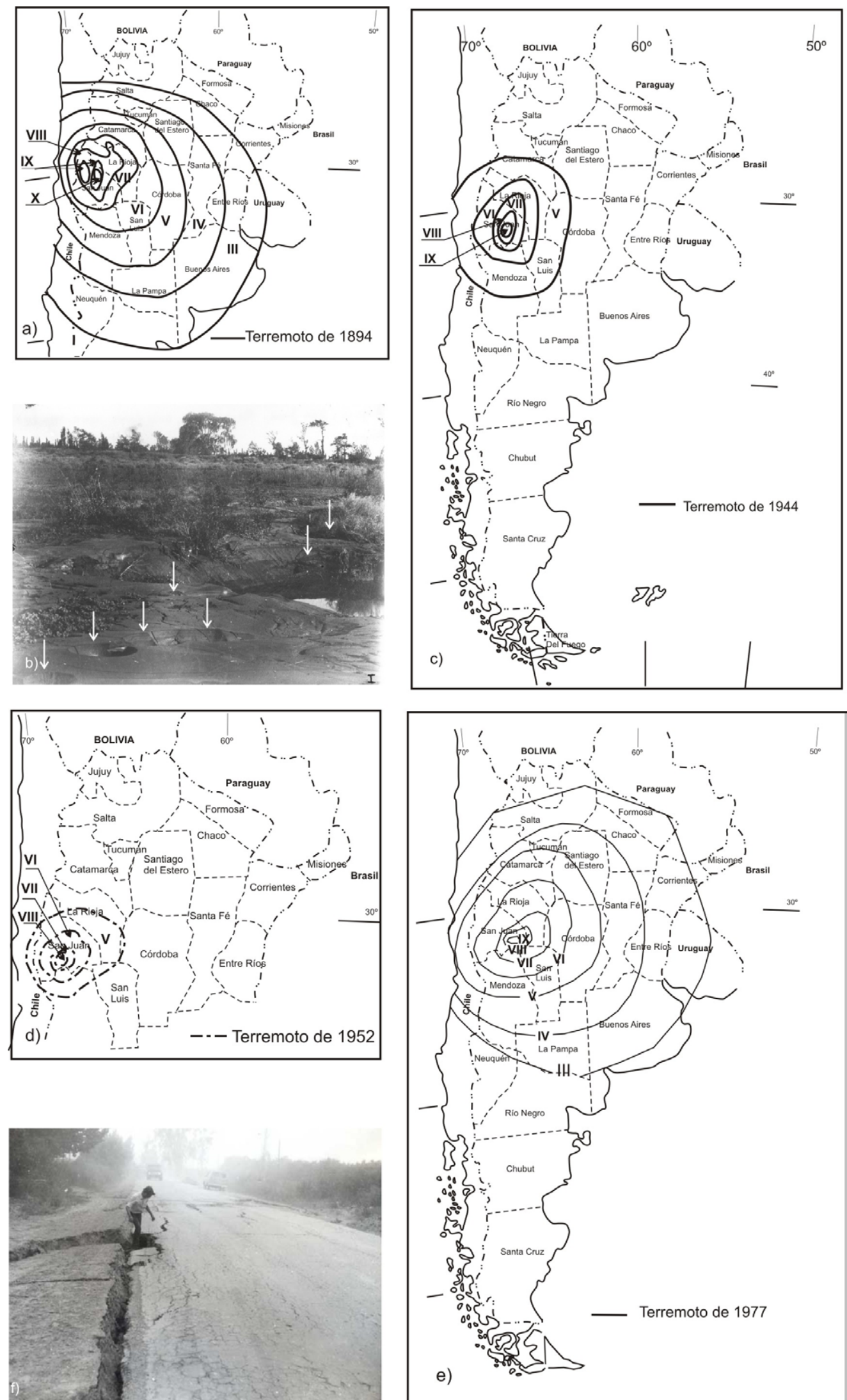

Figura 2. Terremotos históricos de San Juan, a) Mapa de isosistas del terremoto de octubre de 1894, de intensidad X(EMM) en el norte de San Juan, b) Licuefacción de suelos en un área próxima a la ciudad de San Juan, fotografía tomada por Bodenbender, c) Isosistas del terremoto de 1944, de intensidad IX, d) Efectos secundarios del terremoto de 1944, generación de grietas y licuefacción de suelos, e) Isosistas del terremoto de 1952, de intensidad VIII y f) Mapa de isosistas del terremoto de 1977, de intensidad máxima IX al este de la ciudad de San Juan. 
por pliegues y fallas inversas. La estructura de la zona se caracteriza por una faja corrida y plegada de tipo piel gruesa, estructura generada como consecuencia de la compresión ándica. La vergencia general es oriental, con los cordones montañosos de rumbo predominantemente norte-sur.

La Precordillera posee una dirección norte-sur y se ubica en toda la porción central de la provincia de San Juan. Sobre la base de sus características litológicas y estructurales, esta unidad fue dividida en tres subunidades: Occidental, Central y Oriental (Ortiz y Zambrano, 1981). Desde el punto de vista estructural los sectores occidental y central están representados por una faja plegada y corrida epidérmica, mientras que el oriental corresponde a un bloque de basamento con una estructura con la misma vergencia que Sierras Pampeanas. A raíz de este estilo estructural Precordillera Oriental es considerada por algunos autores como parte del dominio tectónico de las Sierras Pampeanas, por la presencia de fallas de alto ángulo y vergencia occidental que exponen en el piedemonte oriental de Precordillera, el basamento (Zapata y Allmendinger, 1996; Jordan et al., 1993; Siame et al., 2002).

La Precordillera Central posee cordones montañosos que se desarrollan a lo largo de toda la provincia de San Juan con rumbo meridional. Estructuralmente es una faja plegada y corrida de piel fina con vergencia hacia el este, constituida por cabalgamientos principales con su nivel de despegue en la secuencia sedimentaria cambro-ordovícica (Allmendinger et al., 1990). La Precordillera Occidental por su parte (Baldis et al., 1982), se caracteriza por la vergencia occidental predominante de las estructuras que la componen.

La Precordillera Oriental está constituida por sierras de rumbo submeridional, en general integradas por estructuras plegadas en forma de grandes anticlinales asimétricos al oeste, cuyos ejes son paralelos a los ejes de los cordones montañosos. Los planos axiales de estos anticlinales buzan al este con alto ángulo, en tanto que en la mayoría de los casos los flancos occidentales se presentan verticales, rebatidos o suelen estar suprimidos por fallas inversas de alto ángulo y rumbo predominantemente norte-sur, que constituirían el límite occidental de Precordillera Oriental.

Las sierras Pampeanas occidentales se caracterizan por ser un sistema de montañas en bloques, limitados por fallas inversas de alto ángulo, con vergencia al oeste y con reactivaciones neotectónicas de las fallas que afectan los piedemontes.

En Argentina, a causa de la interacción entre las placas de América del Sur, Antártica y Nazca, se producen complejos procesos donde distintos factores geológicos controlan el régimen de esfuerzos y deformaciones, por lo que el margen occidental del continente sudamericano presenta una topografía y sismicidad típica de margen activo. A partir de $\operatorname{los} 28^{\circ}$ y hasta los $33^{\circ}$ de latitud sur, se produce un aumento de la actividad sísmica. Allí, la placa oceánica subduce hacia el este, con ángulo menor a $10^{\circ}$, hasta una profundidad de $100 \mathrm{~km}$ aproximadamente, donde toma una posición subhorizontal (flat slab) (Figura 1a). Dentro de este segmento donde la geometría de subducción es subhorizontal, se desarrolla casi el $80 \%$ de la deformación cuaternaria argentina documentada (Costa et al., 2000).

\subsection{Marco tectónico del Neógeno}

Al analizar el marco tectónico neógeno y actual de la región, se identificaron las fuentes de actividad sísmica presentes con algunos parámetros característicos de cada una de ellas, con el fin de establecer si existía una correspondencia con la evidencia neotectónica (Figura 3; Tabla 1).

Al noroeste de la provincia de San Juan, en el piedemonte oriental de Cordillera Frontal se ubican fallas paralelas de rumbo NE, que afectan depósitos aluviales cuaternarios (Perucca et al., 1999; Perucca y Martos, 2012). Las principales son: fallas Infiernillos (1), Cachiyuyal (2), Colangüil-Guañizuil (3) (Figuras 3, 4a), Pismanta-Las Flores (4) y Bella Vista-Angualasto (5) (Figura 3). Existen fallas con rumbo NO y NE subordinadas a las anteriores. Al sur del río San Juan se reconocen fallas inversas de rumbo $\mathrm{N} 20^{\circ} \mathrm{E}$ que buzan entre 30 y $75^{\circ} \mathrm{O}$, como las fallas Río Castaño-Villa Nueva (6).

En el ámbito de Precordillera Occidental se destacan de norte a sur las fallas Las Majaditas (7) (Figura 4b), La Bolsa (8) (Figura 4c), y Punilla (9), inversas con vergencia al oeste $y$, en el caso de las dos últimas, con evidencia de una componente dextral (Figura 3) (Perucca et al., 1999).

Al sur del río San Juan, en el piedemonte occidental de Precordillera occidental, se ubica el sistema de Fallamiento El Tigre (10) (Bastías, 1986). Fazzito et al. (2013) considera una falla subvertical cuyas irregularidades alternan tramos transtensivos y transpresivos, bajo un régimen regional cuaternario de carácter transpresivo, con cauces fluviales y abanicos aluviales desplazados, trincheras, barreales de falla, escarpas a contra pendiente, vertientes y vegetación alineadas (Figura 4d). Siame et al. (1997) determinaron que la falla afecta seis niveles de abanicos aluviales cuyas edades, obtenidas por dataciones cosmogénicas, varían entre 700000 años para los niveles más antiguos y 21000 años para las superficies más recientes hasta el nivel actual. Siame et al. (1997) obtuvieron un desplazamiento lateral derecho de aproximadamente $150 \pm 20 \mathrm{~m}$ y un máximo desplazamiento de $260 \pm 20 \mathrm{~m}$. Estimaron una tasa horizontal de deslizamiento para esta falla de aproximadamente $1-5$ mm/año. Costa et al. (2000) determinaron para la falla El Tigre una longitud de $153 \mathrm{~km}$, un rumbo promedio $\mathrm{N} 10^{\circ} \mathrm{E} \pm$ $6^{\circ}$ y una inclinación promedio medida en una trinchera de $75^{\circ}-80^{\circ} \mathrm{E}$ (Figura 3). Además,señalaron un ramal paralelo a la falla El Tigre denominado falla Cántaro de Oro (11).

Al sur del río San Juan y con rumbo NNO se ubica una escarpa de falla al este, que corresponde a la falla Jarillal (Bastías et al., 1984). Observaciones de Cortés et al. (1997) revelan que al sur de la latitud $32^{\circ}$, la falla se une al cabalgamiento cuaternario Ansilta, de vergencia oriental. La falla Jarillal-Ansilta (12) es inversa y posee una longitud 


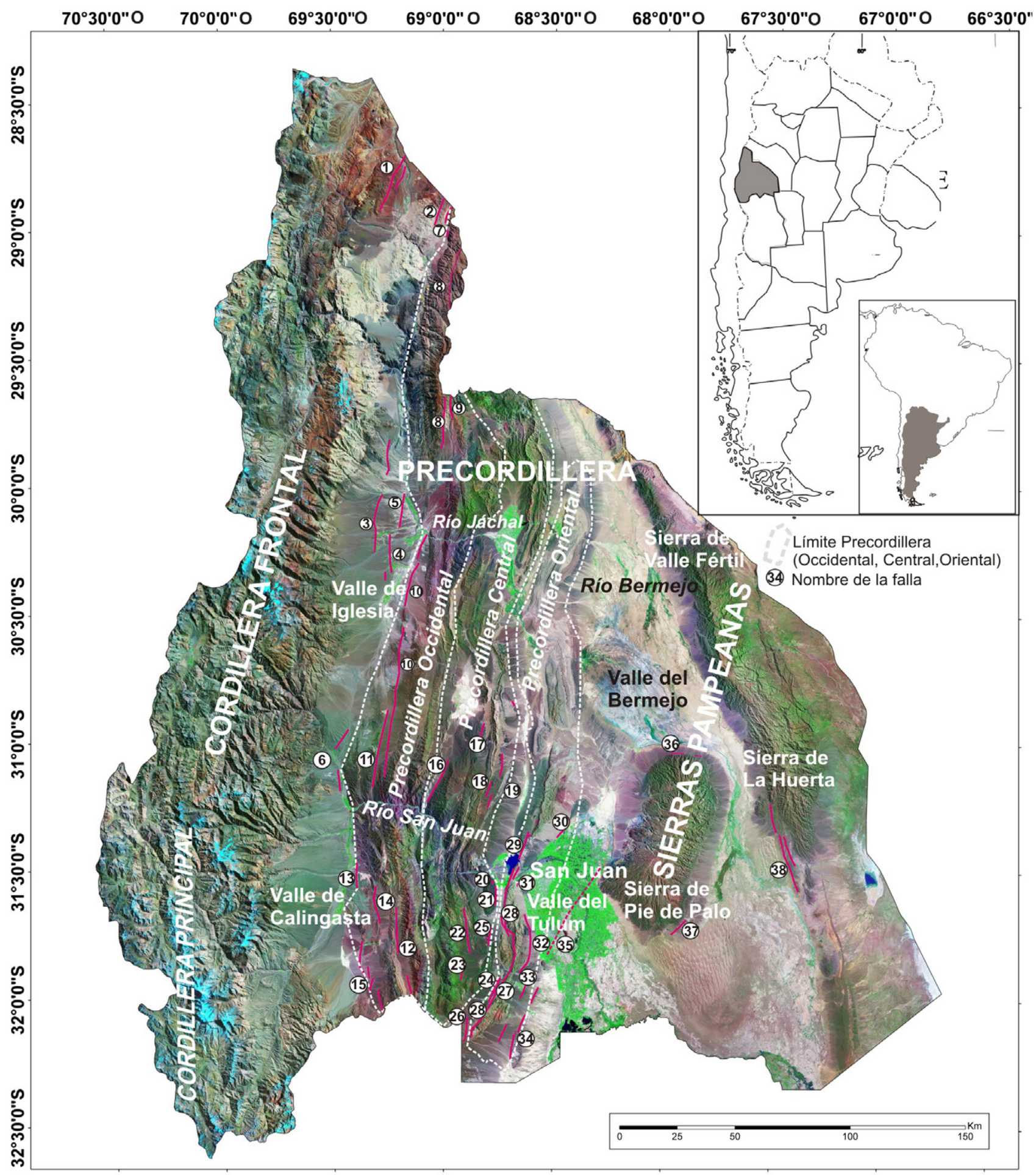

Figura 3. Imagen de la provincia de San Juan en la que se procesaron 8 escenas para formar el mosaico de imágenes satelitales Landsat con las principales fallas de actividad tectónica cuaternaria: 1. Falla Infiernillos, 2. Falla Cachiyuyal, 3. Falla Colanguil-Guañizuil, 4. Falla Pismanta-Las Flores, 5. Falla Bella Vista-Angualasto, 6. Falla Río Castaño-Villa Corral, 7. Falla Las Majaditas, 8. Falla La Bolsa, 9. Falla Punilla, 10. Sistema de Fallamiento El Tigre, 11. Falla Cántaro de Oro, 12. Falla Jarillal-Ansilta, 13. Falla El Alcázar, 14. Falla Cepeda, 15. Falla Barreal-Las Peñas, 16. Falla La Cantera, 17. Falla Las Crucesitas, 18. Falla La Dehesa, 19. Falla Blanquitos, 20. Falla Cerro Zonda Norte, 21 Falla Cerro Zonda Sur, 22. Falla Maradona, 23. Falla Las Osamentas, 24. Falla Cerro La Chilca, 25. Sistema de Falla Papagayos, 26. Falla Acequión-Los Colorados, 27. Falla El Mocho, 28. Falla Villicun-ZondaPedernal, 29. Falla Loma de Las Tapias, 30. Falla La Laja, 31. Falla Marquesado, 32. Falla Rinconada, 33. Falla Los Berros, 34 . Falla Cerro Salinas, 35. Falla Tulum, 36. Falla Pajaritos, 37. Falla Niquizanga, 38. Falla Las Chacras. 
Tabla 1. Fuentes sismogénicas relevantes en la provincia de San Juan: (1) Cinemática de la falla, (2) Longitud total de la falla o sistema de fallas, (3) Rumbo promedio de la traza de falla, (4) buzamiento del plano de falla, (5) Magnitud (Ms) obtenida a partir de la correlación de Slemmons (1982), (6) Magnitud Momento obtenida asignada a cada falla a partir de la correlación de Wells y Coppersmith (1994) con la longitud de ruptura en superficie, (7) Edad estimada del último evento, (8) Tasa de deslizamiento estimadas y (9) Intervalo de recurrencia estimados.

\begin{tabular}{|c|c|c|c|c|c|c|c|c|c|c|}
\hline \multirow{2}{*}{ No } & \multirow{2}{*}{ Fuente } & Tipo & $\mathrm{L}(\mathrm{km})$ & $\mathrm{RB}$ & Buz & Ms & $\mathrm{M}$ & EUM & $\mathrm{Td}(\mathrm{mm} / \mathrm{a})$ & IR (años) \\
\hline & & -1 & -2 & -3 & -4 & -5 & -6 & -7 & -8 & -9 \\
\hline 1 & Falla Infiernillos & Inversa & 20 & $\mathrm{~N} 25^{\circ} \mathrm{E}$ & $\mathrm{O}$ & 6.9 & 6.6 & 6.9 & $0.01-0.1 \mathrm{~mm} /$ año & Desconocido \\
\hline 2 & Falla Cachiyuyal & Inversa & 13 & $\mathrm{~N} 24^{\circ} \mathrm{E}$ & E & 6.7 & 6.4 & $<1.6 \mathrm{Ma}$ & $0.01-0.1 \mathrm{~mm} / \mathrm{año}$ & Desconocido \\
\hline 3 & Falla Colanguil-Guañizuil & Inversa & 25 & $\mathrm{~N} 10^{\circ} \mathrm{E}$ & $\mathrm{O}$ & 6.7 & 7.0 & $<1.6 \mathrm{Ma}$ & $0.01-0.1 \mathrm{~mm} /$ año & Desconocido \\
\hline 4 & Falla Pismanta-Las Flores & Inversa & 18 & $\mathrm{~N} 3^{\circ} \mathrm{O}$ & $\mathrm{O}$ & 6.9 & 6.5 & $<1.6 \mathrm{Ma}$ & $0.01-0.1 \mathrm{~mm} / \mathrm{año}$ & Desconocido \\
\hline 5 & Falla Bella Vista-Angualasto & Inversa & 17 & $\mathrm{~N} 10^{\circ} \mathrm{E}$ & $\mathrm{O}$ & 6.8 & 6.5 & $<1.6 \mathrm{Ma}$ & $0.01-0.1 \mathrm{~mm} / \mathrm{año}$ & Desconocido \\
\hline 6 & Falla Castaño-Villa Corral & Inversa & 10 & $\mathrm{~N} 20^{\circ} \mathrm{E}$ & $30^{\circ}-70 \mathrm{E}$ & 6.6 & 6.2 & $<1.6 \mathrm{Ma}$ & $0.01-0.1 \mathrm{~mm} /$ año & Desconocido \\
\hline 7 & Falla Las Majaditas & Inversa & 20 & $\mathrm{~N} 26^{\circ} \mathrm{E}$ & E & 6.9 & 6.6 & $<1.6 \mathrm{Ma}$ & $0.01-0.1 \mathrm{~mm} /$ año & Desconocido \\
\hline 8 & Falla La Bolsa & Inversa & 20 & $\mathrm{~N} 13^{\circ} \mathrm{E}$ & $\mathrm{O}$ & 6.9 & 6.6 & $<10 \mathrm{ka}$ & Desconocido & Desconocido \\
\hline 9 & Falla Punilla & Inversa & 7 & $\mathrm{~N} 10^{\circ} \mathrm{O}$ & $\mathrm{O}$ & 6.4 & 6.0 & $<10 \mathrm{ka}$ & Desconocido & Desconocido \\
\hline 10 & Sistema El Tigre & Normal/Rumbo dextral & 153 & $\mathrm{~N} 10^{\circ} \mathrm{E} \pm 6^{\circ}$ & $70-80^{\circ} \mathrm{E}$ & 7.9 & 7.6 & $<21 \mathrm{Ka}$ & $1-5 \mathrm{~mm} / \mathrm{año}$ & $500-2000$ \\
\hline 11 & Falla Cántaro de Oro & Inversa? & 12 & $\mathrm{~N} 10^{\circ} \mathrm{E}$ & E? & 6.7 & 6.3 & $<21 \mathrm{Ka}$ & $1-5 \mathrm{~mm} / \mathrm{año}$ & $500-2000$ \\
\hline 12 & Sistema Jarillal - Ansilta & Inversa & 17 & $\mathrm{~N} 9^{\circ} \mathrm{E} \pm 21^{\circ}$ & $\mathrm{O}$ & 6.8 & 6.5 & $<1.6 \mathrm{Ma}$ & $0.05-0.06 \mathrm{~mm} / \mathrm{año}$ & Desconocido \\
\hline 13 & Falla el Alcázar & Inversa & 15 & $\mathrm{~N} 5^{\circ} \mathrm{O} \pm 29^{\circ}$ & $65^{\circ} \mathrm{E}$ & 6.6 & 6.9 & $<1.6 \mathrm{Ma}$ & $0.01-0.1 \mathrm{~mm} /$ año & Desconocido \\
\hline 14 & Falla Cepeda & Inversa & 13 & $\mathrm{~N} 15^{\circ} \mathrm{O} \pm 28^{\circ}$ & $45^{\circ} \mathrm{O}$ ? & 6.4 & 6.6 & $<1.6 \mathrm{Ma}$ & $0.01-0.1 \mathrm{~mm} /$ año & Desconocido \\
\hline 15 & Barreal-Las Peñas & Inversa & 25 & $\mathrm{~N} 15^{\circ} \mathrm{O}$ & $35^{\circ} \mathrm{O}$ & 6.7 & 7.0 & $<1.6 \mathrm{Ma}$ & $0.01-0.1 \mathrm{~mm} /$ año & Desconocido \\
\hline 16 & La Cantera & Inversa & 47 & $\mathrm{~N} 20^{\circ}$ & $20^{\circ} \mathrm{O}$ & 7.0 & 6.7 & $<4.580 \pm 50$ años $\mathrm{AP}$ & $0.01-0.1 \mathrm{~mm} /$ año & Desconocida \\
\hline 17 & Falla Las Crucesitas & Inversa & Desc. & $\mathrm{N} 30^{\circ} \mathrm{E}$ & $30^{\circ}-40^{\circ} \mathrm{O}$ & & & $<1.6 \mathrm{Ma}$ & $0.01-0.1 \mathrm{~mm} /$ año & Desconocido \\
\hline 18 & Falla La Dehesa & Inversa & 60 & $\mathrm{~N} 30^{\circ} \mathrm{E}$ & $60^{\circ} \mathrm{O}$ & 7.5 & 7.2 & $\begin{array}{c}\text { Holoceno } \\
<10000\end{array}$ & $\begin{array}{l}0.01-0.1 \mathrm{~mm} / \text { año } \\
0.01-0.1 \mathrm{~mm} / \text { año }\end{array}$ & Desconocido \\
\hline 19 & Sistema de falla Blanquitos & Inversa & 16 & $\mathrm{~N} 17^{\circ} \mathrm{E}$ & $50^{\circ}-70 \mathrm{E}$ & 6.8 & 6.5 & $\begin{array}{c}\text { Holoceno } \\
<10000\end{array}$ & $\begin{array}{l}0.01-0.1 \mathrm{~mm} / \mathrm{año} \\
0.01-0.1 \mathrm{~mm} / \text { año }\end{array}$ & Desconocido \\
\hline 20 & Falla Cerro Zonda Norte & Inversa & 2.5 & $\mathrm{~N} 40^{\circ} \mathrm{O}$ & $89^{\circ} \mathrm{NE}$ & 5.9 & 5.5 & $<1.6 \mathrm{Ma}$ & $0.01-0.1 \mathrm{~mm} /$ año & Desconocido \\
\hline 21 & Falla Cerro Zonda Sur & Inversa & 10 & $\mathrm{~N} 10^{\circ} \mathrm{E}$ & $10^{\circ}-50^{\circ} \mathrm{O}$ & 6.6 & 6.2 & $34800 \pm 1180 \mathrm{a}$ AP & Desconocida & Desconocido \\
\hline 22 & Falla Maradona & Inversa & 32 & $\mathrm{~N} 12^{\circ} \mathrm{O}$ & $45^{\circ} \mathrm{O}$ & 7.2 & 6.8 & $\begin{array}{c}\text { Holoceno } \\
<10000\end{array}$ & $0.2-1 \mathrm{~mm} /$ año & Desconocido \\
\hline 23 & Falla Las Osamentas & Inversa & 6 & $\mathrm{~N} 10^{\circ} \mathrm{O}$ & $30^{\circ} \mathrm{O}$ & 6.3 & 5.9 & $<1.6 \mathrm{Ma}$ & $0.01-0.1 \mathrm{~mm} / \mathrm{año}$ & Desconocido \\
\hline 24 & Falla Cerro La Chilca & Inversa & 10 & $\mathrm{~N} 15^{\circ} \mathrm{E}$ & $25^{\circ} \mathrm{O}$ & 6.6 & 6.2 & $\begin{array}{c}\text { Holoceno } \\
<10000\end{array}$ & $0.01-0.1 \mathrm{~mm} / \mathrm{año}$ & Desconocido \\
\hline 25 & Sistema de Falla Papagayos & Inversa & 9 & $\mathrm{~N} 175^{\circ} \mathrm{E}$ & $15^{\circ}-25^{\circ} \mathrm{O}$ & 6.5 & 6.2 & $<22.420 \pm 390$ años AP & $0.01-0.1 \mathrm{~mm} / \mathrm{año}$ & Desconocido \\
\hline 26 & Falla Acequión & Inversa & 6 & $\mathrm{~N} 10^{\circ} \mathrm{E}$ & $25^{\circ} \mathrm{O}$ & 6.3 & 5.9 & $<32680 \pm 1580$ años $\mathrm{AP}$ & $0.01-0.1 \mathrm{~cm} /$ año & Desconocido \\
\hline 27 & Falla El Mocho & Inversa & 8.5 & $\mathrm{~N} 20^{\circ} \mathrm{E}$ & $70^{\circ} \mathrm{E}$ & 6.5 & 6.1 & $<1.6 \mathrm{Ma}$ & $0.01-0.1 \mathrm{~mm} / \mathrm{año}$ & Desconocido \\
\hline 28 & Falla Villicum-Zonda-Pedernal & Inversa & 145 & $\mathrm{~N} 20^{\circ} \mathrm{E}$ & $40^{\circ}-60^{\circ} \mathrm{E}$ & 7.9 & 7.6 & $<1.6 \mathrm{Ma}$ & & Desconocido \\
\hline 29 & Falla Loma de Las Tapias & Inversa & 9 & $\mathrm{~N} 22^{\circ} \mathrm{E} \pm 7$ & $80^{\circ} \mathrm{E}$ & 6.8 & 6.5 & $\begin{array}{c}\text { Holoceno } \\
<10000\end{array}$ & $0.8 \pm 0.5 \mathrm{~mm} /$ año & $7.5 \mathrm{ka}$ \\
\hline 30 & Falla La Laja & Inversa & 7 & $\mathrm{~N} 40^{\circ} \mathrm{E}$ & $30-45^{\circ} \mathrm{E}$ & 6.9 & 6.2 & $\begin{array}{c}1944 \\
7\end{array}$ & $0.6-1.2 \mathrm{~mm} / \mathrm{año}$ & $\begin{array}{c}3.9 \pm 0.3 \mathrm{ka} \\
\text { (Rockwell et al } . \\
\text { 2014) }\end{array}$ \\
\hline 31 & Falla Marquesado & Inversa & 28 & $\mathrm{~N} 13^{\circ} \mathrm{E} \pm 24$ & $25^{\circ}-35^{\circ} \mathrm{E}$ & 7.1 & 6.8 & $\begin{array}{l}\text { Holoceno } \\
<10000\end{array}$ & $0.27 \mathrm{~mm} /$ año & $1.9-2.0 \mathrm{ka}$ \\
\hline & & & & & & & & Holoceno & & \\
\hline 32 & Falla Rinconada & Inversa & 26 & $\mathrm{~N} 22^{\circ} \mathrm{E} \pm 13$ & $25^{\circ}-42^{\circ} \mathrm{E}$ & 7.1 & 6.7 & $<10000$ & $0.15 \mathrm{~mm} / \mathrm{año}$ & $2.5-2.8 \mathrm{ka}$ \\
\hline 33 & Falla Los Berros & Inversa & 19 & $\mathrm{~N} 13^{\circ} \mathrm{E} \pm 9$ & $30^{\circ}-40^{\circ} \mathrm{E}$ & 6.9 & 6.5 & $\begin{array}{c}\text { Holoceno } \\
<10000\end{array}$ & $0.1-1 \mathrm{~mm} /$ año & Desconocido \\
\hline & & & & & & & & Holoceno & & \\
\hline 34 & Falla Cerro Salinas & Inversa & 15 & $\mathrm{~N} 17^{\circ} \mathrm{E}$ & $15^{\circ}-25^{\circ} \mathrm{E}$ & 6.8 & 6.4 & $<10000$ & $0.13 \mathrm{~mm} /$ año & $2.5-2.8 \mathrm{ka}$ \\
\hline 35 & Falla Tulum & Inversa? & Desc. & $\mathrm{N} 15^{\circ}-20^{\circ} \mathrm{E}$ & & & & Desconocido & & \\
\hline 36 & Falla Pajaritos & Sinestral & 14 & $\mathrm{~N} 85^{\circ} \mathrm{E}$ & Desconocido & 6.7 & 6.4 & $\begin{array}{c}\text { Holoceno } \\
<10000\end{array}$ & $0.1-1 \mathrm{~mm} /$ año & Desconocido \\
\hline 37 & Falla Niquizanga & Inversa & 65 & $\mathrm{~N}^{\circ} 21^{\circ} \mathrm{E} \pm 22$ & Al Este & 7.5 & 7.2 & $\begin{array}{c}1977 \\
7.4\end{array}$ & Desconocida & Desconocido \\
\hline 38 & Falla Las Chacras & Inversa/sinistral & 60 & $\mathrm{~N} 28^{\circ} \mathrm{W} \pm 12$ & $40^{\circ}-60^{\circ} \mathrm{E}$ & 7.5 & 7.1 & $\begin{array}{c}\text { Holoceno } \\
<10000\end{array}$ & $1-5 \mathrm{~mm} / \mathrm{año}$ & $5 \mathrm{ka}$ \\
\hline
\end{tabular}



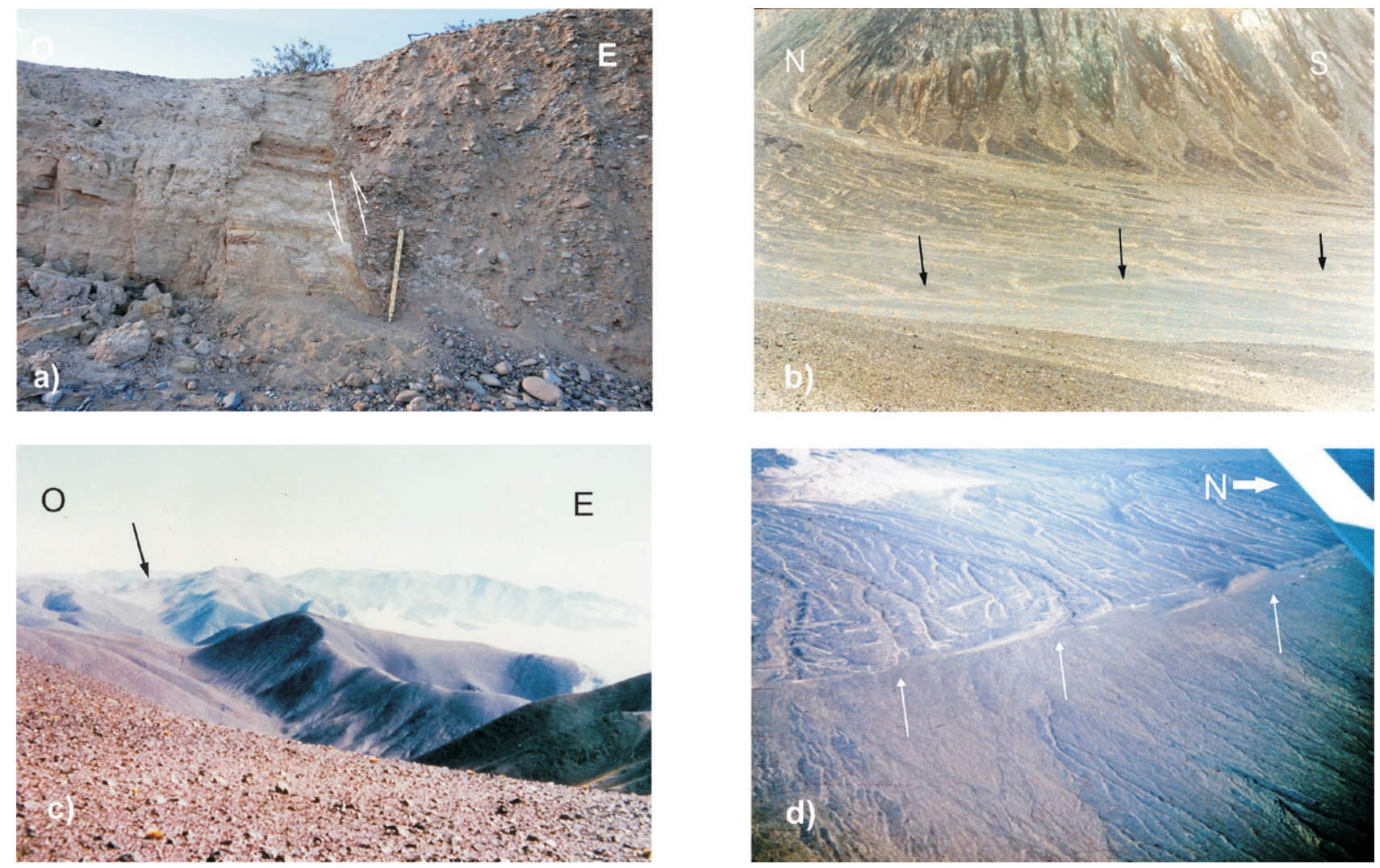

Figura 4. Fallas con actividad tectónica cuaternaria en el piedemonte de Cordillera Frontal y Precordillera Occidental. a) Trinchera de la falla ColangüilGuañizuil, inversa y de ángulo con vergencia al oeste. La falla coloca depósitos de abanicos aluviales de edad pleistocénica media sobre depósitos finos asignados al Pleistoceno Superior (Perucca y Martos, 2012), b) Falla Las Majaditas, ubicada en el piedemonte occidental de Precordillera. La falla es inversa y buzante al este, y afecta abanicos aluviales pleistocénicos? c) Valle lineal y falla La Bolsa, en la porción central del cordón montañoso d) Falla El Tigre, rumbo deslizante dextral, ubicada en el piedemonte occidental de Precordillera. La escarpa a contrapendiente afecta niveles de abanicos aluviales del Pleistoceno Medio a Superior.

aproximada de $17 \mathrm{~km}$, con rumbo promedio de $\mathrm{N} 9^{\circ} \mathrm{E} \pm 21^{\circ}$, buza al oeste con un valor no especificado, con escarpa al este. Quartino et al. (1971) señalaron numerosas fallas que cortan depósitos cuaternarios, como la falla El Alcázar (13), inversa, con longitud de $15 \mathrm{~km}$, rumbo general $\mathrm{N}^{\circ} \mathrm{O} \pm 29^{\circ}$ y bloque oeste hundido. La falla Cepeda (14), posiblemente inversa y con inclinación al oeste, corta los sedimentos aluviales cuaternarios contiguos al frente, generando una notoria escarpa con ladera al este. Esta falla posee una longitud aproximada de $13 \mathrm{~km}$ con un rumbo promedio $\mathrm{N} 15^{\circ} \mathrm{O} \pm 28^{\circ}$ (Figura 3 ).

Cortés y Cegarra (2004) describieron en el extremo sur de la Precordillera, un extenso cinturón transpresivo cenozoico, denominado Barreal-Las Peñas (15) de $150 \mathrm{~km}$ de longitud, de orientación NNO, constituido por bloques montañosos escalonados, delimitados por fallas inversas y zonas de cizalla, con componentes de desplazamiento de rumbo sinestral (Figura 3).

En el ámbito de Precordillera Central se destaca la falla La Cantera (16), que inclina al oeste y desplaza depósitos aluviales del Pleistoceno-Holoceno (Mingorance, 1994, 1998; Millán y Perucca, 2011). Presenta geoformas características que evidencian su actividad neotectónica, tales como cauces "colgados" y obturados, escarpas de falla, escarpas de flexión y lagunas de falla (sag ponds), entre otras (Figuras 3, 5a). La falla inclina entre $10^{\circ} \mathrm{O}$ en la porción norte a $30^{\circ} \mathrm{O}$ hacia el sur. La escarpa de la falla principal posee una altura promedio de $14 \mathrm{~m}$. La longitud total de la falla es de $47 \mathrm{~km}$, su rumbo promedio $\mathrm{N} 20^{\circ} \mathrm{E}$ y afecta niveles aluviales del Pleistoceno Superior-Holoceno. Millán y Perucca (2011) dataron un nivel edáfico incipiente afectado por la falla, obteniendo una edad $\mathrm{C}^{14}$ no calibrada de $4580 \pm 50$ años AP, lo que correspondería al Holoceno medio. Finalmente, un pequeño cauce actual deflectado por un escarpe de $0.30 \mathrm{~m}$ podría corresponder al sismo de 1924 (M 6.0).

La falla Las Crucesitas (17) es inversa con vergencia al este, inclina entre $30^{\circ}$ y $40^{\circ} \mathrm{O}$, con azimut $210^{\circ}$ (Figuras $3,5 b)$. Se midieron estrías en el plano de falla cuyo buzamiento es de $60^{\circ} \mathrm{NO}$. Esta falla no aflora en superficie, constituyendo un cabalgamiento ciego.

La falla La Dehesa (18) se ubica en el piedemonte oriental de la sierra homónima, es inversa y posee una longitud de $60 \mathrm{~km}$, con azimut $210^{\circ}$ y buzamiento $60^{\circ} \mathrm{O}$ (Figura 3). Hacia el este se ubica el sistema de fallamiento Blanquitos (19) (Figura 3), con fallas subparalelas de 

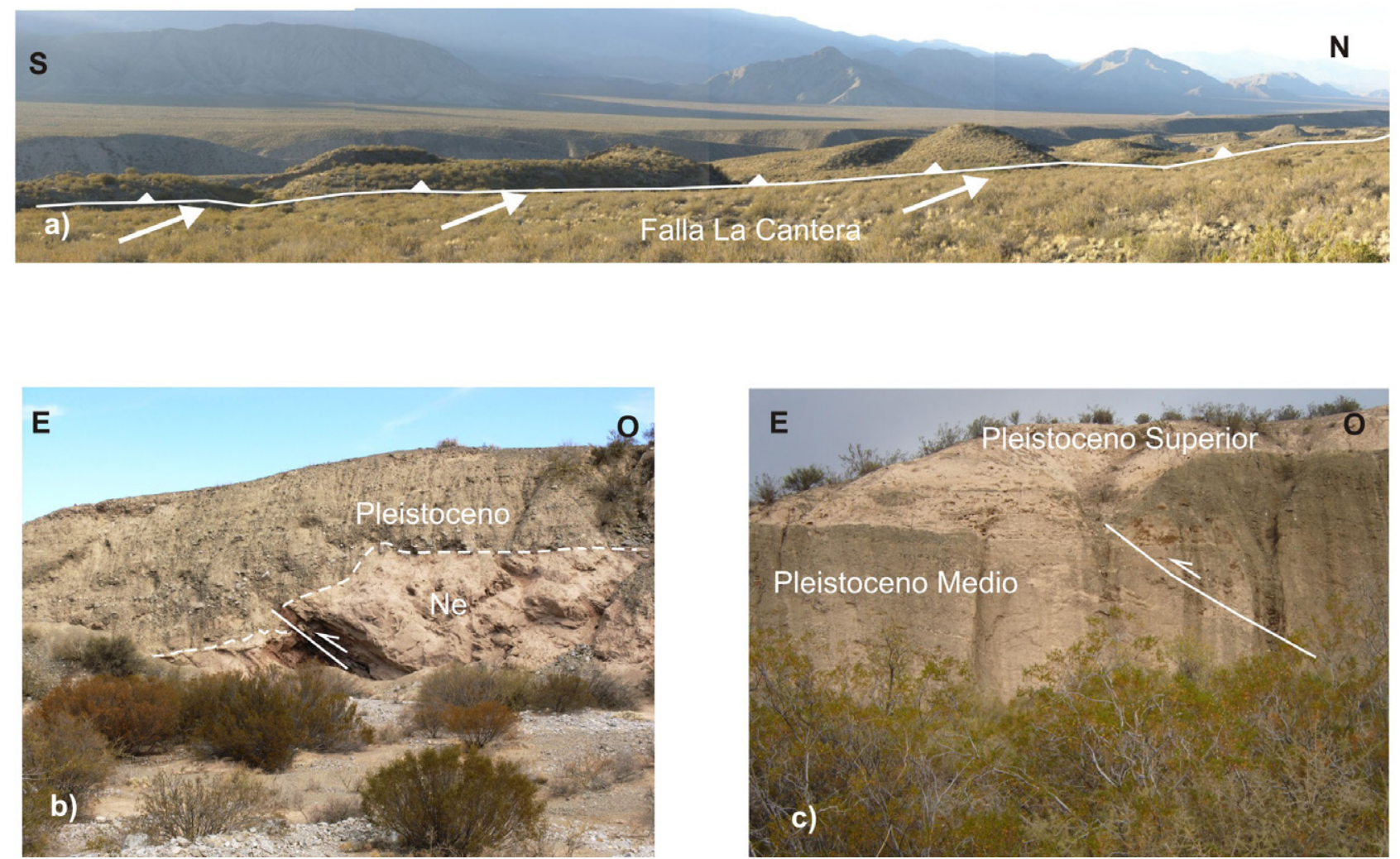

Figura 5. Fallas con actividad tectónica cuaternaria en Precordillera Central. a) Escarpa compuesta al este de la falla La Cantera, b) Falla inversa Las Crucesitas, en la que se aprecian rocas del Neógeno (Ne) sobre depósitos aluviales asignados tentativamente al Pleistoceno c) Falla Papagayos, afectando niveles aluviales y lacustres de edad pleistocénica (Perucca et al., 2012a).

rumbo meridional y vergencia occidental, que afectan los abanicos aluviales provenientes del sector oeste, los cuales se encuentran fuertemente perturbados por la tectónica moderna, con cauces fuertemente incididos, diseños de la red de drenaje y pendientes aluviales anómalas y vertientes alineadas. El rumbo de las fallas es $\mathrm{N} 10^{\circ} \mathrm{E}$ y buzan $70^{\circ} \mathrm{E}$. $\mathrm{Su}$ longitud aproximada es de $16 \mathrm{~km}$. Paredes y Perucca (2000) dataron un nivel de travertino en el plano de la falla, que arrojó una edad de $28422 \pm 1335$ años AP, encontrando evidencias de reactivación posteriores, lo que sugiere actividad durante el Pleistoceno Tardío-Holoceno.

Hacia el sur del río San Juan, se localizan fallas de edad cuaternaria, con rumbo $\mathrm{N} 45^{\circ} \mathrm{O}$ y buzamiento $89^{\circ} \mathrm{O}$ que afectan los distintos niveles de abanicos aluviales presentes en la zona, que corresponden a la falla Cerro Zonda Norte (20) (Figura 3) (Perucca et al., 2012a).

La falla Cerro Zonda sur (21) es inversa de azimut $170^{\circ}$, que inclina $15^{\circ} \mathrm{O}$. Niveles de Cuaternario sobreelevados y con pendiente anómala hacia el oeste (opuestas a la pendiente del piedemonte) y la presencia de vertientes alineadas señalarían la actividad tectónica cuaternaria para esta falla, de unos $10 \mathrm{~km}$ de longitud (Figura 3). En una trinchera natural se reconocieron rocas del Devónico sobre depósitos aluviales del Pleistoceno Tardío. La datación de un nivel de carbonatos en el plano de la falla, arrojó una edad $\mathrm{C}^{14}$ de $34800 \pm 1180$ AP (Perucca et al., 2012a).
Más al sur, Bastías et al. (1984), Perucca (1990), Perucca et al. (1990), Perucca y Paredes (2004), Moreiras y Banchig (2008), y Perucca et al. (2012a), entre otros, localizaron la falla Maradona (22). La falla posee azimut $12^{\circ}$, es inversa e inclina $45^{\circ} \mathrm{O}$ y las alturas de la escarpa al este varían entre $3 \mathrm{~m}$, en el sector sur, a $20 \mathrm{~m}$ en el tramo norte (Perucca y Paredes, 2004). La falla, tiene una extensión de $32 \mathrm{~km}$ y afecta niveles aluviales que corresponden al Pleistoceno (Figura 3) y también una terraza de posible edad holocena. Hacia el sur, fue denominada por Perucca et al. (2009) falla Las Osamentas (23), de azimut $350^{\circ} \mathrm{e}$ inclinación $30^{\circ} \mathrm{O}$ (Figura 3). Hacia el este de la falla Las Osamentas se encuentra la falla Cerro La Chilca (24), con una longitud de $11 \mathrm{~km} \mathrm{y} \mathrm{rumbo} \mathrm{N} 15^{\circ} \mathrm{E}$. Es un cabalgamiento que inclina entre $25^{\circ}$ y $30^{\circ} \mathrm{O}$ que afecta niveles aluviales del Pleistoceno.

$\mathrm{Al}$ este de la falla Maradona, se ubicaron fallas inversas paralelas, con escarpas al este, vergencia oriental y rumbo $\mathrm{N}-\mathrm{S}$, descritas someramente por Moreiras y Banchig (2008). Perucca et al. (2012a) denominan estas fallas como Sistema de falla Papagallos (25), cuya longitud estiman en $9 \mathrm{~km}$. La falla más occidental posee un rumbo $\mathrm{N} 8^{\circ} \mathrm{O}$, inclina $15^{\circ} \mathrm{a}$ $20^{\circ} \mathrm{O}$ y afecta una secuencia de abanico aluvial pleistocena y un nivel de tosca que dataron en $22420 \pm 390$ años AP (Perucca et al., 2012a) (Figura 4c). En el extremo sur de San Juan y al este de la Precordillera Central se ubica la falla 
Acequión (26) (Perucca y Paredes, 2004) o cabalgamiento Los Colorados (Ahumada y Costa, 2009) (Figura 3). Perucca et al. (2012b) determinaron para esta falla un rumbo $\mathrm{N} 0^{\circ}$ a $10^{\circ}$ y buzamiento $26^{\circ} \mathrm{O}$. La escarpa está formada por dos resaltos adyacentes de $6 \mathrm{~m}$ y $1.80 \mathrm{~m}$ de altura.

En el ámbito de Precordillera oriental se ubica la falla El Mocho (27) (Uliarte et al., 1987; Perucca y Onorato, 2011), caracterizada por su traza rectilínea, con rumbo $\mathrm{N} 20^{\circ} \mathrm{E}$ y escarpa a contrapendiente, que afecta el abanico aluvial del Pleistoceno. La falla inversa posee vergencia al oeste con ángulos elevados $\left(70^{\circ} \mathrm{E}\right)$. Su longitud aproximada es de 8.5 km (Figuras 3, 6a).

En el piedemonte occidental de la Precordillera Oriental se destaca la falla regional Villicum-Zonda-Pedernal (28), localizada en el piedemonte occidental de Precordillera Oriental, posee una longitud de $145 \mathrm{~km}$ y un rumbo $\mathrm{N} 20^{\circ} \mathrm{E}$. Al norte del río San Juan se denomina falla Loma de Las Tapias (29), con longitud de $18 \mathrm{~km}$, rumbo N22 ${ }^{\circ}$ y buzamiento $78^{\circ} \mathrm{E}$, y afecta depósitos aluviales de edad cuaternaria, con escarpas degradadas y discontinuas que
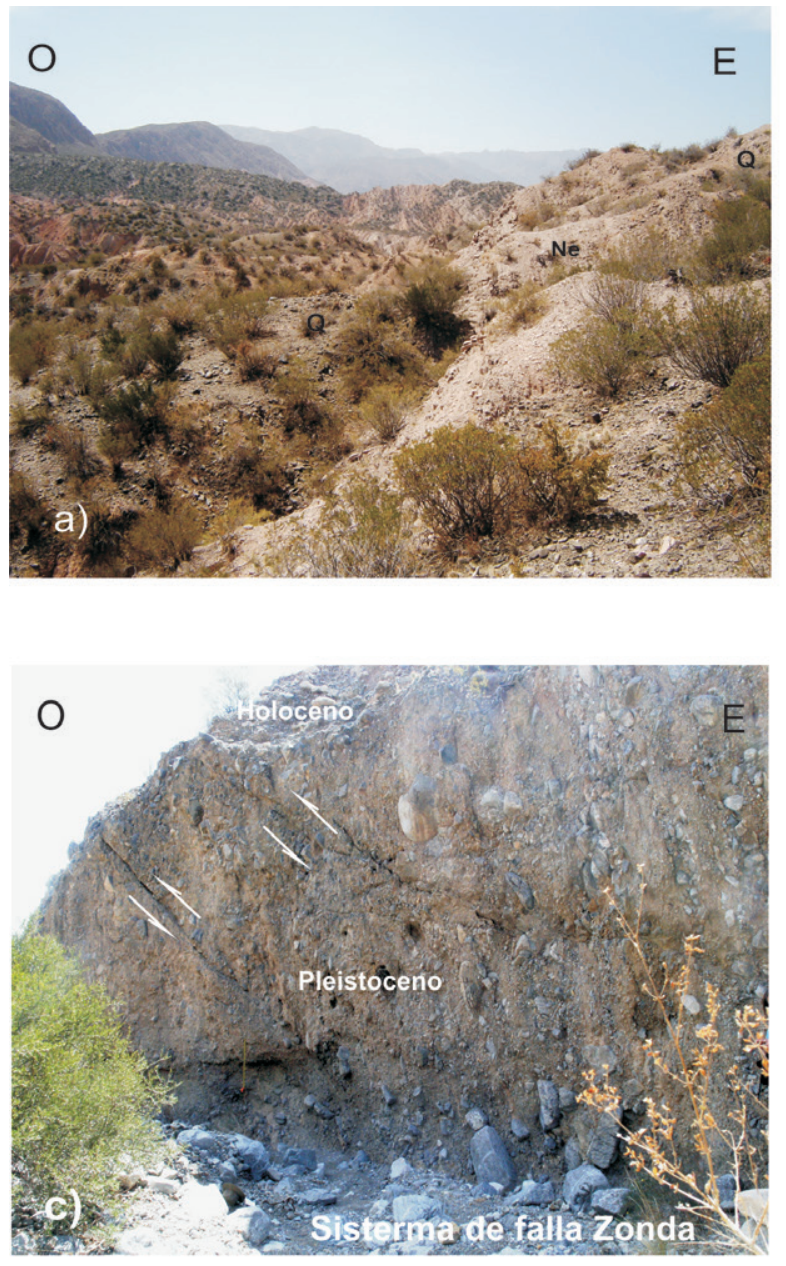

miran al oeste, de unos $10 \mathrm{~m}$ de altura (Figura 6b). La datación de un nivel carbonoso ubicado en una laguna de falla (sag pond) arrojó una edad de $21260 \pm 201$ años. Siame et al. $(2002,2006)$ propusieron una edad mínima de $1.9 \pm$ $0.8^{10} \mathrm{Be}-\mathrm{kyr}$ para la superficie piedemontaña reciente y de $6.9 \pm 1.0$ y $18.7 \pm 2.3{ }^{10} \mathrm{Be}-\mathrm{kyr}$ respectivamente para las superficies sobreelevadas Q1 y Q2. Estos autores estimaron una tasa de levantamiento de $0.7 \pm 0.3 \mathrm{~mm} / \mathrm{año} \mathrm{y} \mathrm{de}$ acortamiento de $0.8 \pm 0.5 \mathrm{~mm} / \mathrm{año}$. Al sur del río San Juan, la falla posee un azimut $330^{\circ}$ y buzamiento entre $40^{\circ}$ y $66^{\circ} \mathrm{E}$, y afecta a depósitos aluviales pleistocénicos (Figura 6c).

En el piedemonte oriental de la Precordillera Oriental, la zona de fracturación moderna constituye un sistema de fallas inversas con escarpas subparalelas, en general, en contra de la pendiente regional. Las fallas poseen un rumbo promedio $\mathrm{N} 40^{\circ} \mathrm{E}$, en superficie inclinan aproximadamente entre $30^{\circ}$ y $45^{\circ} \mathrm{E}$ y afectan los distintos niveles de abanicos aluviales. La falla La Laja (30) está vinculada al sismo del 15 de enero de 1944, de Ms 7.0 (Figuras 3, 6d). La ruptura superficial asociada se estimó entre 6 y $8 \mathrm{~km}$ y el
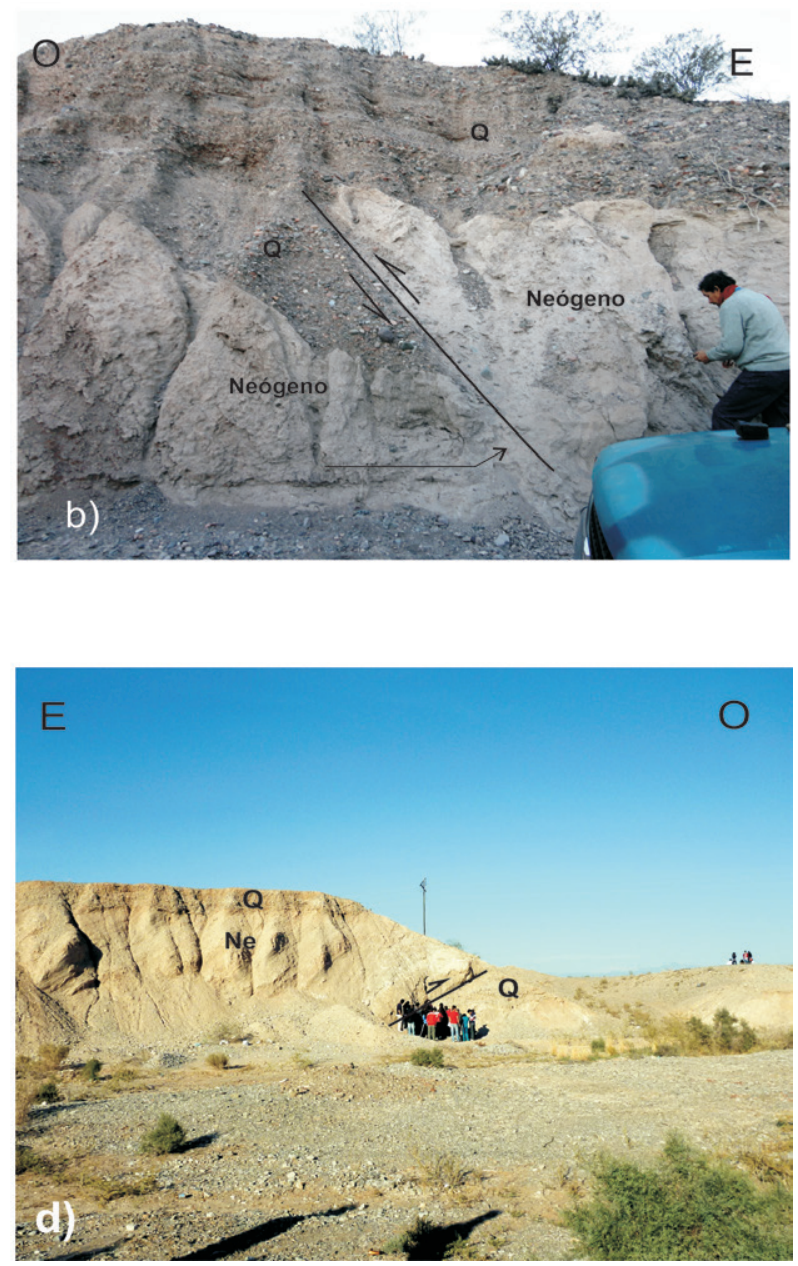

Figura 6. Fallas con actividad tectónica cuaternaria en Precordillera Oriental, a) Escarpa al oeste de la falla El Mocho, que coloca rocas del Neógeno (Ne) sobre depósitos aluviales cuaternarios, b) Falla Loma de Las Tapias, inversa y buzante al este, que sobrepone rocas del Neógeno sobre depósitos aluviales pleistocénicos (Q), c) Falla Sierra Chica, inversa y con vergencia al oeste, afectando niveles aluviales pleistocénicos, d) Falla La Laja, en el piedemonte oriental de Precordillera Oriental, inversa y buzante al este. 
desplazamiento vertical entre 30 y $60 \mathrm{~cm}$ (Castellanos, 1945; Perucca y Paredes, 2003). Un análisis detallado efectuado por Ragona (2007) en trincheras artificiales, datadas por OSL y $\mathrm{C}^{14}$ dio como resultado la ocurrencia de nueve eventos de deslizamiento de la falla para los últimos $\sim 32 \mathrm{ka}$. Este autor concluyó que la recurrencia promedio para los últimos ocho intervalos es de $4.1 \pm 0.5 \mathrm{ka}$, coincidente con la determinada entre los eventos individuales.

$\mathrm{Al}$ sur del río San Juan, la falla Marquezado (31) posee una longitud de $28 \mathrm{~km}$ y un rumbo $N 13^{\circ} \mathrm{E} \pm 24$ y una inclinación promedio entre 24 y $35^{\circ} \mathrm{E}$ (Costa et al., 2000). Afecta depósitos aluviales de edad pleistocénica hasta terrazas holocénicas (Figura 3). En una trinchera realizada por el INPRES (1982), se observa una falla de rumbo $\mathrm{N} 37^{\circ} \mathrm{E}$, que inclina $29^{\circ} \mathrm{SE}$ y que ha desplazado un horizonte aluvial entre 1.75 y $1.50 \mathrm{~m}$. Un nivel arenoso fino con restos de carbón permitió determinar su edad en $2505 \pm 160$ años.

Más al sur, la falla Rinconada (32) se ubica a lo largo del faldeo oriental de la sierra Chica de Zonda (Figura 3). Martos $(1993,1995)$ reconoció una falla principal inversa que inclina al este y fallas asociadas menores subparalelas con inclinaciones entre $25^{\circ}$ y $42^{\circ} \mathrm{E}$. Estas fallas afectan sedimentos cuaternarios asignados al Pleistoceno-Holoceno. La longitud de la falla es de $26 \mathrm{~km}$ y su rumbo promedio es $\mathrm{N} 2^{\circ} \mathrm{E} \pm 13^{\circ}$. Las escarpas miran al oeste y tienen un trazado cóncavo hacia el frente montañoso y sus alturas varían de 1 a $3 \mathrm{~m}$.

La falla Los Berros (33) se reconoce por la presencia de tres trazos subparalelos de fallas inversas, subparalelas y meridionales, que afectan niveles aluviales cuaternarios (Figura 3). Presenta escarpas a contrapendiente con la cara libre hacia el oeste y vertientes de agua alineadas. Su longitud aproximada es de $19 \mathrm{~km}$ y la falla es inversa y buza al este (Martos, 1995). La falla Cerro Salinas (34), posee rumbo submeridional, con fallas secundarias subparalelas, inversas y de bajo ángulo con vergencia al oeste y con escarpas que miran al oeste (Figura 3). La falla principal posee una longitud de $15 \mathrm{~km}$ (Martos, 1995).

El área de fallamiento Tulum (35) se ubica al este de la ciudad de San Juan (Figura 3). Las fallas principales poseen un rumbo NNO. Son fallas inversas de alto ángulo cerca de la superficie y fallas normales de rumbo ENE, que han elevado o hundido bloques de rocas precuaternarias y que afectan depósitos de edad cuaternaria. Este conjunto de fallas ha sido reconocido por datos geofísicos y perforaciones (Zambrano y Suvires, 2008; Perucca y Ruiz, 2013) ya que no afloran en superficie.

En el ámbito de Sierras Pampeanas, en el piedemonte septentrional de la sierra de Pie de Palo se ubica la falla Pajaritos (36), de rumbo E-O y desplazamiento sinestral, que afecta los abanicos aluviales provenientes de esta sierra (Figuras 3,7a), mientras que en el extremo sureste de la sierra, se ubica la falla Niquizanga (37) (Figuras 3, 7b) (Perucca y Paredes, 2004). La escarpa de la falla Niquizanga tiene su cara libre hacia el oeste, las alturas oscilan entre 3 y $7 \mathrm{~m}$; afecta niveles de terraza y abanicos aluviales. La longitud total de la falla es de $20 \mathrm{~km}$. Durante el sismo de 1977, se produjo un nuevo desplazamiento y las nivelaciones geodésicas revelaron la existencia de una deformación permanente del suelo de $1.20 \mathrm{~m}$, mientras que el desplazamiento de las escarpas no superó los $0.30 \mathrm{~m}$ (Figura 7c).

La falla Las Chacras (38) se ubica en el faldeo occidental de las sierras de Valle Fértil-La Huerta. Posee aproximadamente $60 \mathrm{~km}$ de evidencias continuas de actividad y afecta depósitos del Cuaternario (Figuras 3, 7d). Son fallas inversas de rumbo promedio $\mathrm{N} 28^{\circ} \mathrm{O} \pm 12$, que inclinan entre $45^{\circ}$ y $60^{\circ} \mathrm{E}$, con una aparente componente de desplazamiento lateral izquierdo (Perucca y Paredes, 2004). El intervalo de recurrencia para esta falla se estima en 5000 años (INPRES,1982) y la tasa de deslizamiento entre $1-5$ mm/año (Pérez et al., 1997).

\section{Discusión y conclusiones}

La cadena montañosa de los Andes, entre los $27^{\circ}$ y $33^{\circ} \mathrm{S}$, resulta de la convergencia entre las placas Nazca y Sudamérica. La compresión asociada con el movimiento de las placas es responsable de la formación de los relieves observados en el territorio sanjuanino y de los sistemas de fallas con actividad cuaternaria que afectan la región. Parte de esta convergencia se absorbe a lo largo de los principales sistemas de falla, que limitan el relieve y constituyen la mayor parte de la deformación activa conocida hasta el presente en el territorio argentino.

Los principales sistemas activos se extienden paralelamente a los piedemontes de las tres cadenas montañosas principales (Cordillera Frontal, Precordillera y Sierras Pampeanas), en general con rumbo N-S.

En el piedemonte oriental de Cordillera Frontal se desarrollan fallas subparalelas con actividad tectónica durante el Cuaternario, cuyas longitudes alcanzan decenas de kilómetros y afectan principalmente depósitos de edad pleistocénica.

La estructura de la Precordillera es compleja, ya que las Precordillera Central y Occidental constituyen una faja plegada y corrida de piel fina con vergencia oriental, mientras que la Precordillera Oriental y Sierras Pampeanas poseen un estilo de piel gruesa con vergencia al oeste. En general, predominan los cabalgamientos y retrocabalgamientos longitudinales, combinados con fallas oblicuas de orientación noroeste, asociados a una notoria reactivación cuaternaria del relieve.

Los segmentos con actividad tectónica durante el Cuaternario constituyen probables fuentes sismogénicas para la región. La presencia de deformaciones holocénicas y la elevada sismicidad histórica (en el siglo XX) e instrumental de la región es representativa de la potencialidad de estas estructuras neotectónicas, como generadoras de terremotos destructivos para la región.

El registro de sismos históricos en esta región del país 

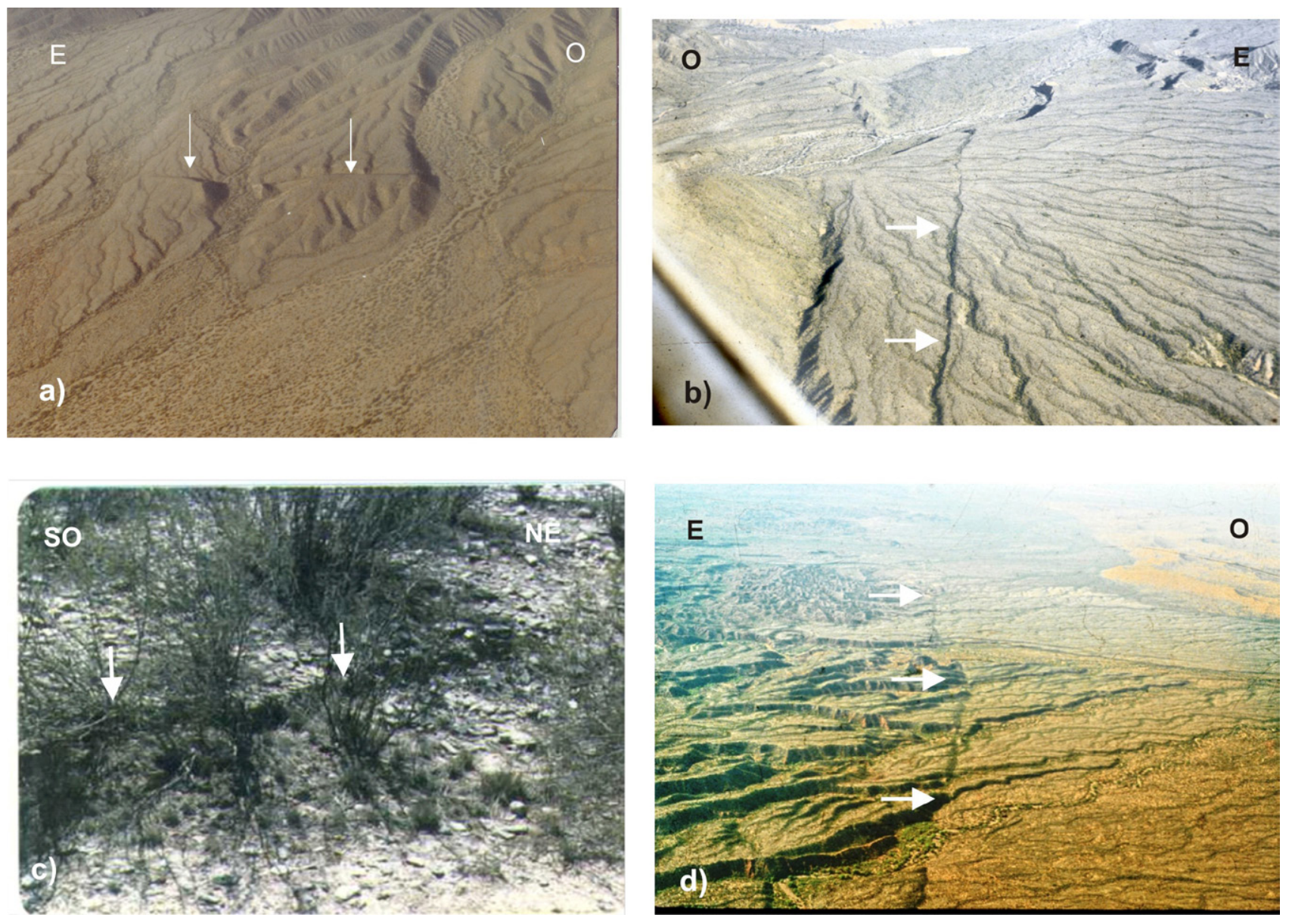

Figura 7. Fallas activas en el ámbito de Sierras Pampeanas Occidentales, a) Vista aérea de la falla Pajaritos, con rumbo E-O y afectando distintos niveles aluviales cuaternarios, b) Vista aérea oblicua de la falla Niquizanga, de rumbo casi N-S y sobre depósitos de abanico aluvial, c) escarpa generada en la falla Niquizanga, durante el terremoto de 1977, d) Vista aérea de la falla Las Chacras, de trazo marcadamente rectilíneo y con escarpa al oeste. La falla afecta los distintos niveles de abanico aluvial cuaternarios.

comienza aproximadamente a principios del siglo XVIII, después de la llegada de los primeros colonizadores españoles. Sin embargo, como la densidad poblacional en esa época era muy baja o nula, sumado al marcado aislamiento que sufrían los pobladores, probablemente sólo se registraron los eventos catastróficos. La escasa densidad poblacional en esta parte del país fue quizás la causa principal de la falta de registros que mencionen tales eventos. Por ello, es poco probable que esta falta de datos sea representativa de un ciclo asísmico regional anterior al siglo XX, ya que la información neotectónica recopilada indica que el rango de actividad ha sido continuo a través de gran parte del Cuaternario.

Finalmente, la obtención de nuevos estudios detallados de sismicidad, GPS, neotectónica y microtectónica podrán conducir a un mejor entendimiento de los procesos de deformación continental en el territorio y contribuir a una estimación más realista de la amenaza sísmica en la región.

\section{Agradecimientos}

La presente contribución fue financiada con fondos del proyecto PIP 0799-2010 (CONICET), CICITCA 21E/870 y PICTO UNSJ-AGENCIA 013. Los autores agradecen a los revisores, Dr. Luca Ferrari y Dr. José Ramón Hernández Santana por sus sugerencias y comentarios que contribuyeron a mejorar este trabajo.

\section{Referencias}

Ahumada, E., Costa, C., 2009, Antithetic linkage between oblique Quaternary thrusts at the Andean front, Argentine Precordillera, 28, 207-216.

Allmendinger, R., Figueroa, D., Snyder, D., Beer, J., Mpodozis, C., Isacks B., 1990, Foreland shortening and crustal balancing in the Andes at $30^{\circ} \mathrm{S}$ latitude: Tectonics 9, 789-809.

Alvarado, P., Beck, S., 2006, Source Characterization of the San Juan (Argentina) crustal earthquakes of 15 January 1944 (Mw 7.0) and 11 June 1952 (Mw 6.8): Earth and Planetary Science Letters, 243, 615-631. 
Amos, A.J., Rolleri, E.O., 1965, El Carbónico marino en el valle de Calingasta-Uspallata (San Juan-Mendoza): Boletín de Informaciones Petroleras, 368, 50-71.

Anderson, M., Alvarado, P., Zandt, G., Beck, S.L., 2007, Geometry and brittle deformation of the subducting Nazca Plate, central Chile and Argentina: Geophysical Journal International, 171(1), 419-434.

Baldis, B., Uliarte, E., Beresi, M., Bordonaro, O., Vaca, A., 1982, Síntesis evolutiva de la Precordillera Argentina, en Quinto Congreso Latinoamericano de Geología: Buenos Aires, Argentina, 399-445.

Bastías, H., 1986, Fallamiento Cuaternario en la región sismotectónica de Precordillera: San Juan, Argentina, Universidad Nacional de San Juan, tesis doctoral, $147 \mathrm{p}$.

Bastías, H., Weidmann, N., Pérez, M., 1984, Dos zonas de fallamiento PlioCuaternario en la Precordillera de San Juan, en Noveno Congreso Geológico Argentino: Bariloche, Río Negro, Asociación Geológica Argentina, 329-341.

Bodenbender, G., 1895, El terremoto argentino del 27 de octubre de 1894: Córdoba, Boletín de la Academia Nacional de Ciencias, 48 p.

Casa, A., Yamín, M., Wright, E., Costa, C., Coppolecchia, M., Cegarra, M., 2011, Deformaciones Cuaternarias de la República Argentina, Sistema de Información Geográfica: Instituto de Geología y Recursos Minerales, Servicio Geológico Minero Argentino, Publicación 171, v1.0 DVD

Castellanos, A., 1945, Cuatro Lecciones sobre terremotos. Parte B: El terremoto de San Juan: Asociación Cultural de Conferencias de Rosario, Publicación, 6, 77-243,

Cortés, J.M., Cegarra, M., 2004, Plegamiento cuaternario transpresivo en el piedemonte suroccidental de la Precordillera sanjuanina: Buenos Aires, Asociación Geológica Argentina, Serie D, Publicación Especial 7, 68-75,

Cortés, J.M., González-Bonorino, G., Koukharsky, M., Brodtkorb, A., 1997, Memoria de la Hoja Geológica 3369-03, Yalguaraz, provincias de San Juan y Mendoza: Buenos Aires, Instituto de Geología y Recursos Minerales, $120 \mathrm{p}$.

Costa, C., Machette, M., Dart, R., Bastías, H., Paredes, J., Perucca, L., Tello, G., Haller, K., 2000, Map and Database of Quaternary Faults and Folds in Argentina: U.S. Geological Survey Open-File Report 00-0108, $75 \mathrm{p}$.

Fazzito, S., Cortés, J., Rapalini, A., Terrizzano, C., 2013, The geometry of the active strike-slip El Tigre Fault, Precordillera of San Juan, Central-Western Argentina: integrating resistivity surveys with structural and geomorphological data, 102, 1447-1466.

Groeber, P., 1951, La Alta Cordillera entre las latitudes $34^{\circ}$ y $29^{\circ} 30^{\prime}$ : Buenos Aires, Instituto Investigaciones de las Ciencias Naturales. Museo Argentino de Ciencias Naturales Bernardino Rivadavia, $352 \mathrm{p}$.

Harrington, H., 1944, El sismo de San Juan del 15 de enero de 1944: Corporación para la Promoción del Intercambio S.A., 79 p., Buenos Aires.

INPRES, 1977, El Terremoto de San Juan del 23 de noviembre de 1977: Informe Preliminar, 102 p., San Juan.

INPRES, 1982, Microzonificación sísmica del valle del Tulum. Provincia de San Juan: Resumen Ejecutivo, 120 p., San Juan.

INPRES, 1993, La verdadera dimensión del problema sísmico en la provincia de San Juan: Publicación Técnica 18, 46 p., San Juan.

INPRES, 2009, Listado de terremotos históricos, catálogo on-line. http:// www.inpres.gov.ar/

Jordan, T.E., Allmendinger, R.W., Damanti, J.F., Drake, R., 1993, Chronology of motion in a complete thrust belt: the Precordillera, 30-31 ${ }^{\circ} \mathrm{S}$, Andes Mountains: Journal of Geology, 101, 135-156.

Martos, L.M., 1993, Evidencias de actividad tectónica en el Pleistoceno superior-Holoceno, Quebrada del Molino, Pocito, San Juan, Argentina, en Décimo Tercer Congreso Geológico Argentino: Mendoza, Argentina, Asociación Geológica Argentina, 258-265.

Martos, L.M., 1995, Análisis morfo-estructural de la faja pedemontana oriental de las sierras de Marquesado, Chica de Zonda y Pedernal: Su aplicación para prevenir riesgos geológicos: San Juan, Argentina, Universidad Nacionalde San Juan, San Juan, tesis doctoral, 554 p.
Millán, J.L., Perucca, L.P., 2011, Análisis neotectónico del extremo norte del sobrecabalgamiento La Cantera, provincia de San Juan, Argentina: Revista Mexicana de Ciencias Geológicas, 18, 337-348.

Mingorance, F., 1994, Distribution of the active faulting in the Central Precordillera thrust Belt, North of San Juan river, San Juan-western Argentina: Master' Thesis, University of Tokyo, Japan, 68 p.

Mingorance, F., 1998, Evidencias de paleoterremotos en la falla activa La Cantera-Cinturón de empuje de la Precordillera, San Juan, Argentina, en Décimo Congreso Latinoamericano de Geología: Buenos Aires, Argentina, 161-166.

Moreiras, S., Banchig, A., 2008, Further evidences of Quaternary activity of the Maradona faulting, Precordillera Central, Argentina, en 7th International Symposium on Andean Geodynamics: Nice, France, Extended Abstracts, 344-347.

Ortiz, A., Zambrano, J., 1981, La provincia geológica de Precordillera Oriental, en Octavo Congreso Geológico Argentino: San Luis, Argentina, Asociación Geológica Argentina, 59-74.

Paredes, J., Perucca, L., 2000, Fallamiento cuaternario en la depresión de Matagusanos, San Juan, Argentina: Revista de la Asociación Geológica Argentina, 55, 23-30.

Pérez, M., Astorga, A., Monllor, J., Araujo, M., 1997, Relevamiento planialtimétrico-geológico de la falla Las Chacras, en la quebrada del Barro, en Octavo Congreso Geológico Chileno: Antofagasta, Chile,Universidad Católica del Norte, 210-214.

Perucca, L., 1990, Sistema de fallamiento La Dehesa-Maradona-Acequión, San Juan, Argentina,en Décimo Congreso Geológico Argentino: San Juan, Argentina, Asociación Geológica Argentina, 431-434.

Perucca, L., Paredes, J., 2003, Fallamiento cuaternario en la zona de La Laja y su relación con el terremoto de 1944, Departamento Albardón, San Juan, Argentina: Revista Mexicana de Ciencias Geológicas, 20-26.

Perucca, L., Paredes, J., 2004, Descripción del Fallamiento Activo en la Provincia de San Juan en Miranda, S., Herrada, A., Sisterna, J. (eds.), Tópicos de Geociencias. Un volumen de estudios sismológicos, geodésicos y geológicos en homenaje al Ing. Fernando SéptimoVolponi, Editorial UNSJ, 269-309, San Juan.

Perucca, L.,Moreiras, S., 2006, Liquefaction phenomena associated with historical earthquakes in San Juan and Mendoza provinces, Argentina: Quaternary International, 158, 96-109.

Perucca, L., Onorato, R., 2011, Fallas con actividad cuaternaria en el corredor tectónico Matagusanos-Maradona-Acequión entre los ríos de La Flecha y del Agua. Provincia de San Juan: Revista de la Asociación Geológica Argentina, 68, 39-52.

Perucca, L., Martos, L., 2012, Geomorphology, tectonism and Quaternary landscape evolution of the central Andes of San Juan $\left(30^{\circ} \mathrm{S}-69^{\circ} \mathrm{W}\right)$, Argentina: Quaternary International, 253, 80-90.

Perucca, L., Ruiz, F., 2014, New data on neotectonic contractional structures in Precordillera, south of Río de la Flecha: structural setting addressed by gravity and magnetic data. San Juan, Argentina: Journal of South American Earth and Sciences, 50, 1-11.

Perucca, L., Sánchez, A., Uliarte, E., 1990, Morfoneotectónica en la zona norte del corredor tectónico Matagusanos-Maradona-Acequión, San Juan, Argentina, en Décimo Congreso Geológico Argentino: San Juan, Argentina, Asociación Geológica Argentina, 435-438.

Perucca, L., Paredes, J., Tello, G., Bastías, H., 1999, Fallamiento activo en el área norte del sistema de fallamiento El Tigre, San Juan-La Rioja: Revista de la Asociación Geológica Argentina, 54, 206-214.

Perucca, L., Pérez, M., Navarro, C., 2006, Fenómenos de licuefacción asociados a terremotos históricos. Su análisis en la evaluación del peligro sísmico en la Argentina: Revista de la Asociación Geológica Argentina, 61, 567-578.

Perucca, L., Moreiras, S., Bracco, A., 2009, Determination of Seismogenic Structures and Earthquake Magnitude from Seismites in Holocene Lacustrine Deposits. Precordillera Range, Central-Western Argentina: Journal of Iberian Geology, 10-20.

Perucca, L.P., Lara, G., Vargas, N., 2012a, Nueva evidencia de actividad tectónica cuaternaria en la depresión Zonda-Maradona, provincia de San Juan: Revista Asociación Geológica Argentina, 69, 97-105. 
Perucca, L., Audemard, F., Pantano, A., Vargas, N., Avila, C., Onorato, M., 2012b, Vergencias opuestas Cuaternarias en el área de Acequión, Precordillera de San Juan (Argentina): Revista de la Sociedad Geológica de España, 25, 3-13.

Pilger, R.H., 1981, Plate reconstructions, aseismic ridges, and low angle subduction beneath the Andes: Geological Society of America Bulletin 92, 448-456

Quartino, B., Zardini, R., Amos, A., 1971, Estudio y exploración geológica de la región Barreal-Calingasta, provincia de San Juan, República Argentina: Revista de la Asociación Geológica Argentina, 1, 1-185.

Ragona, D., 2007, Advanced Methods and Techniques in Paleoseismology: San Diego, U.S.A., University of California, tesis doctoral, 155 p.

Ramos, V.A., Cristallini, E.O., Pérez, D., 2002, The Pampean flat-slab of the Central Andes: Journal of South American Earth Sciences, 15, 59-78.

Siame, L.L., Bourles, D., Sebrier, M., Bellier, O., Castano, J., Araujo, M., Pérez, M., Raisbeck, G., Yiou, F., 1997, Cosmogenic dating from 20 to $700 \mathrm{ka}$ of a series of alluvial fan surfaces affected by El Tigre fault, Argentina: Geology, 25, 975-978.

Siame, L.L., Bellier, O., Sébrier, M., Bourlès, D.L., Leturmy, P., Perez, M., Araujo, M., 2002, Seismic hazard reappraisal from combined structural geology, geomorphology and cosmic ray exposure dating analyses: the Eastern Precordillera thrust system (NW-Argentina): Geophysical Journal International, 150, 241-260.

Siame, L.L., Bellier, O., Sébrier, M., 2006, Active Tectonics in the Argentine Precordillera and Western Sierras Pampeanas:Revista de la Asociación Geológica Argentina, 61, 604-619.
Slemmons, D.B., 1982, Determination of design earthquake magnitudes for microzonation, en Proceedings of the Third International Earthquake Microzonation Conference Vol. 1: Washington, D.C., E.U.A., National Science Foundation, 119-130.

Tello, G., Perucca, L., 1993, El sistema de fallamiento Precordillera Oriental y su relación con los sismos históricos de 1944 y 1952, San Juan, Argentina, en Décimo segundo Congreso Geológico Argentino: Mendoza, Argentina, Asociación Geológica Argentina, 258-265.

Uliarte, E., Bastías, H., Ruzycki, L., 1987, Morfología y Neotectónica en el cerro La Chilca, Pedernal. San Juan, en Décimo Congreso Geológico Argentino: Tucumán, Argentina, Asociación Geológica Argentina, 227-230.

Wells, D.L., Coppersmith, K.J., 1994, New empirical relationships among magnitude, rupture length, rupture width, and surface displacements: Bulletin of the Seismological Society of America, 84, 974-1002.

Zambrano, J.,Suvires, G., 2008, Actualización en el límite entre Sierras Pampeanas occidentales y Precordillera Oriental, en la provincia de San Juan: Revista de la Asociación Geológica Argentina, 63, 110-116.

Manuscrito recibido: Junio 20, 2013.

Manuscrito corregido recibido: Marzo 10, 2014.

Manuscrito aceptado: Marzo 20, 2014. 